Elsevier

GENE 03050

\title{
Cloning of cDNAs encoding human interphotoreceptor retinoid-binding protein (IRBP) and com- parison with bovine IRBP sequences
}

(Recombinant DNA; nucleotide sequence; signal peptide; glycosylation; glycolipoprotein; evolution; retina; four-fold amino acid repeats)

\author{
Jing-Sheng Si, Diane E. Borst, T. Michael Redmond and John M. Nickerson \\ Laboratory of Retinal Cell and Molecular Biology, National Eye Institute, National Institutes of Health, Bethesda, MD 20892 \\ (U.S.A.)
}

Received by J. Piatigorsky: 22 December 1988

Revised: 13 February 1989

Accepted: 17 February 1989

\section{SUMMARY}

We have determined the sequence of the human interphotoreceptor retinoid-binding protein mRNA from three separately isolated cDNAs. The sequence is $4.28 \mathrm{~kb}$ long and encodes a protein of 1247 amino acids (aa) including a putative signal peptide and propeptide. The sequence is shorter (by about $1.67 \mathrm{~kb}$ ) than the bovine mRNA with the major difference in the lengths located in the $3^{\prime}$-untranslated region. We suggest that this resulted from an insertion in the bovine gene or a large deletion from the human gene. The insertion/deletion is flanked on either side by sequences that are similar in the bovine and human sequences. Like the bovine polypeptide, the deduced protein sequence from the human cDNA contains a fourfold repeat, with each repeat containing about 300 aa. Among the four repeats, the identity is about 30-40\%. The identity between the complete bovine and human polypeptide sequences is $84 \%$. The identity between the nucleotide sequences is $83 \%$ (excluding the major insertion/deletion). Comparison with the bovine gene indicates that the human sequence may lack about 5-10 bp at the 5' end of the cDNA; it, however, includes a poly(A) tail at the $3^{\prime}$ end. Thus, the human sequence is virtually full length, is similar to the bovine sequence, and contains a striking fourfold repeat.

\section{INTRODUCTION}

Interphotoreceptor retinoid-binding protein (IRBP) is a large glycolipoprotein (Wiggert et al., 1977 ; 1979) found in the IPM of the retina

Correspondence to: Dr. J.M. Nickerson, Laboratory of Retinal Cell and Molecular Biology, National Eye Institute, National Institutes of Health, Bldg. 6, Room 224, Bethesda, MD 20892 (U.S.A.) Tel. (301)496-2669; Fax (301)496-1759.
(Bunt-Milam and Saari, 1983) and to a lesser extent in the pineal (Rodrigues et al., 1986). The IPM fills an extracellular space bounded by photoreceptor neurons, Muller glial cells, and the retinal pigment epithelium. IRBP is synthesized and secreted by

Abbreviations: aa, amino acid(s); hp, base pair(s); IPM, interphotoreceptor matrix; IRBP, interphotoreceptor retinoid-binding protein; kb, kilobase(s) or $1000 \mathrm{bp}$; nt, nucleotide(s); oligo, oligodeoxyribonucleotide; UTR, untranslated region. 


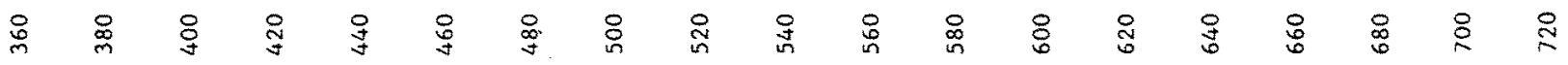

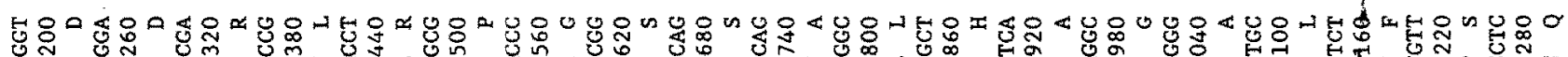

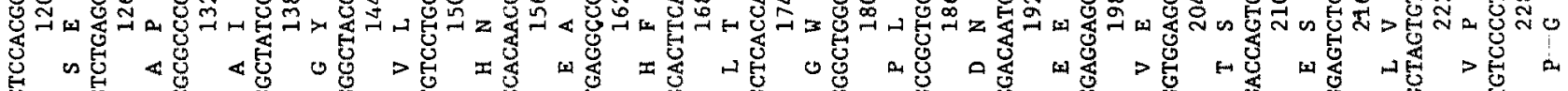

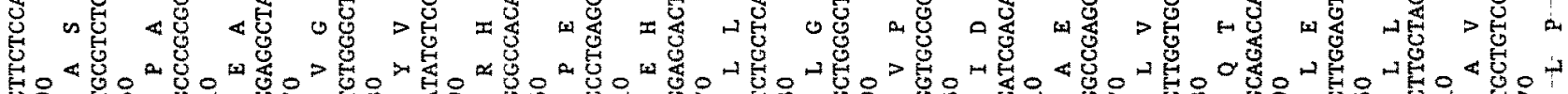

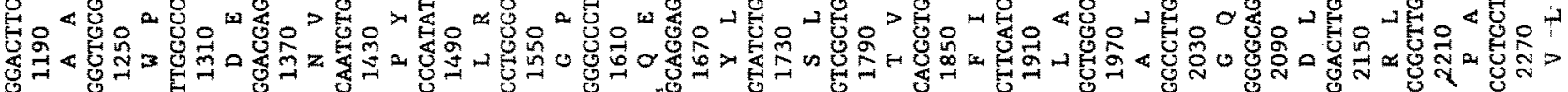

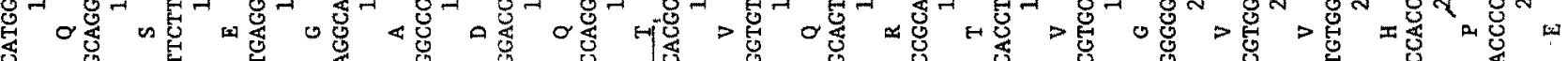

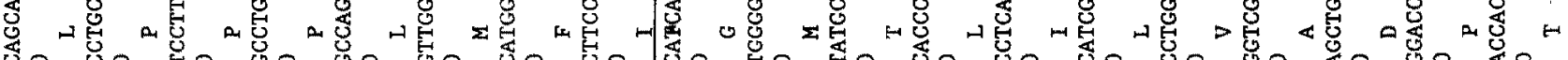

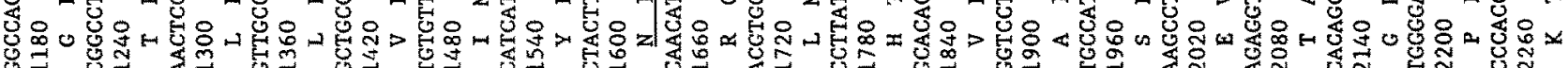

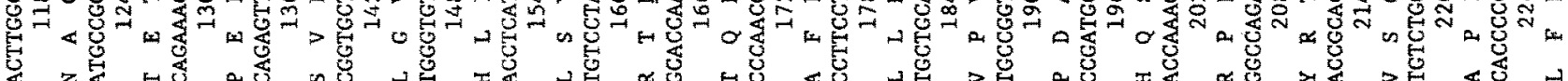

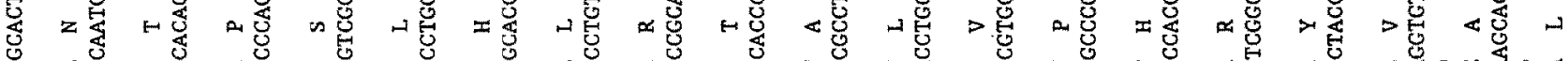

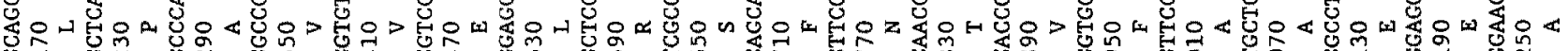

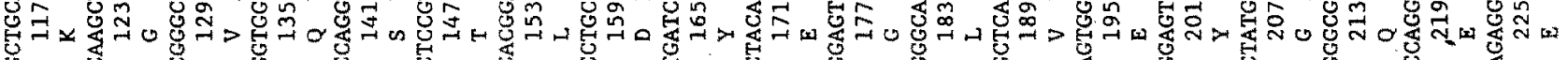

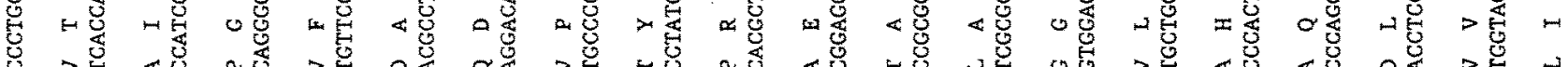

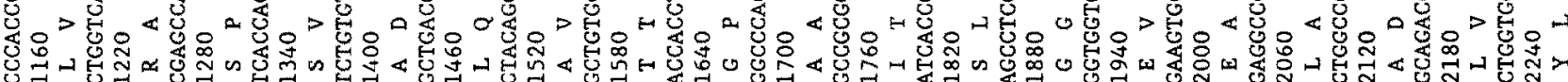

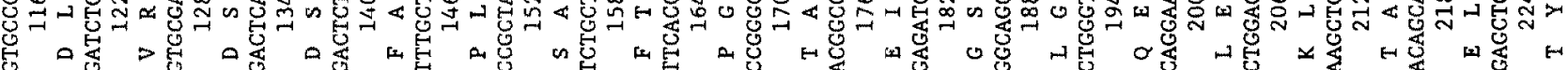

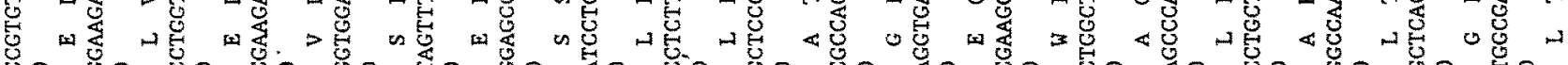

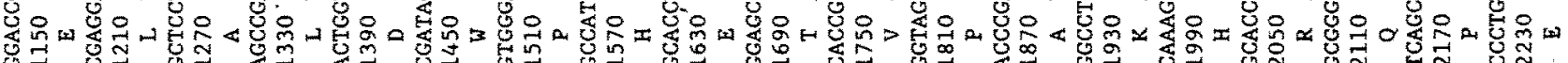

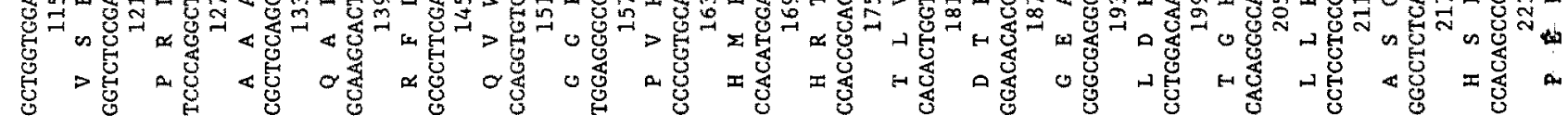

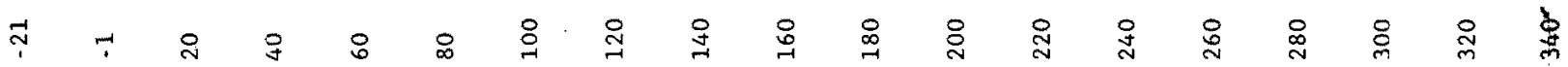

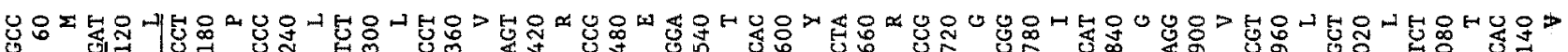

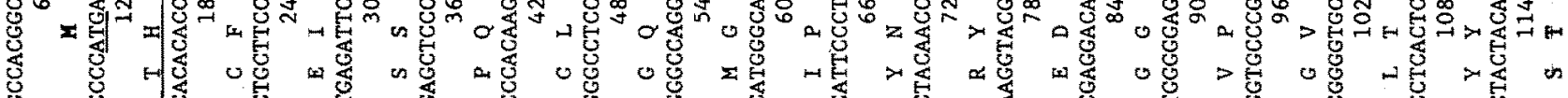
尊

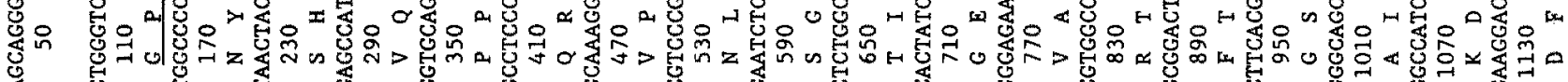

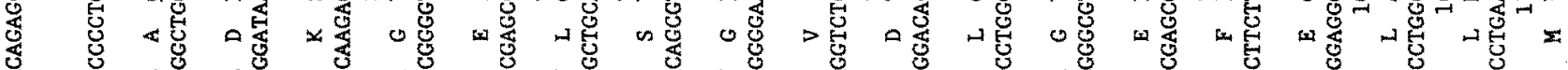

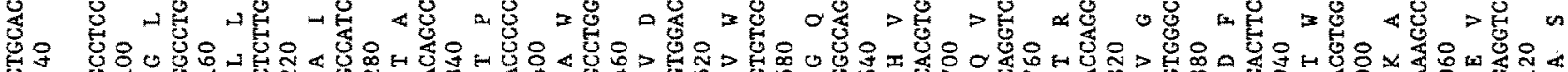

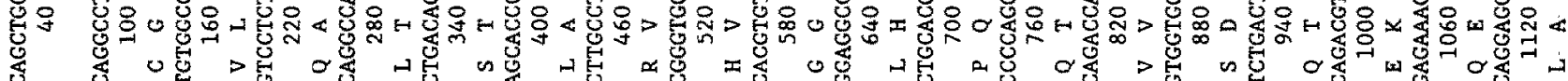

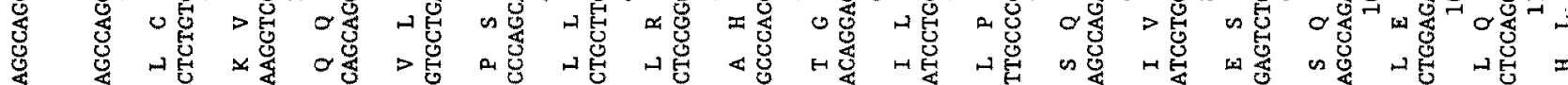

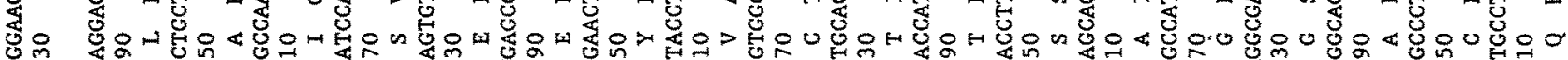

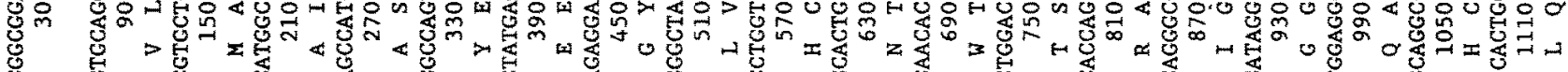

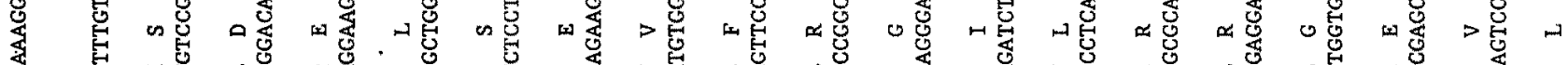

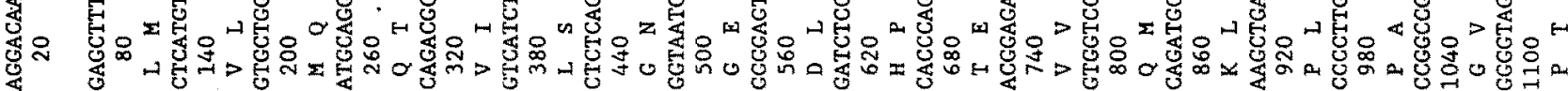

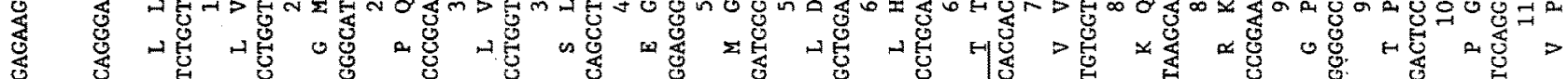

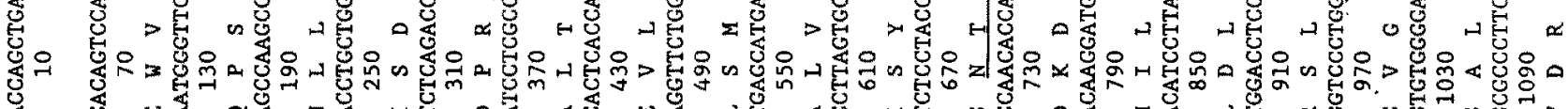

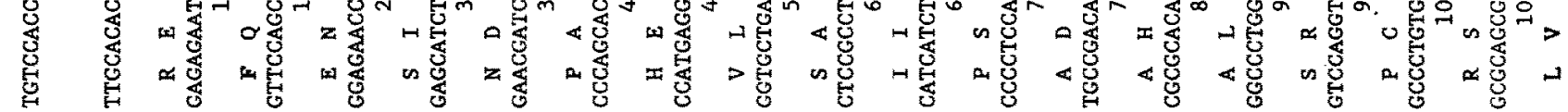




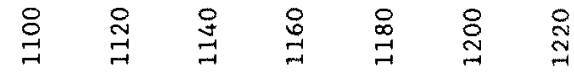

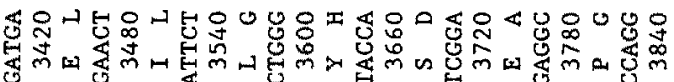

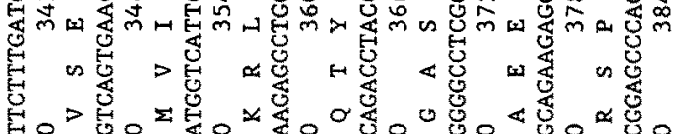

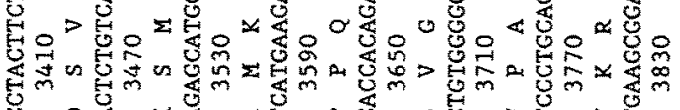

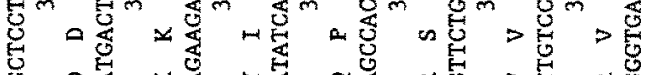

焉8

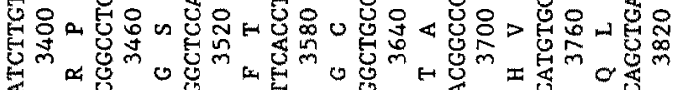

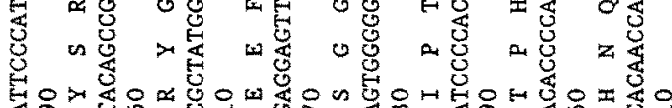

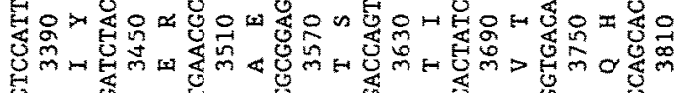

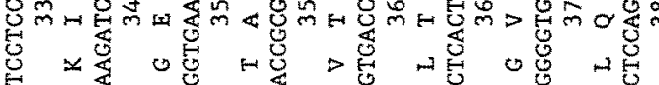

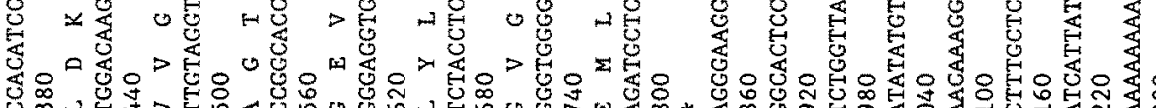

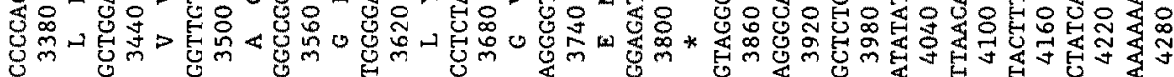

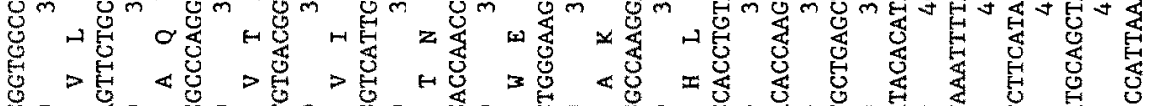

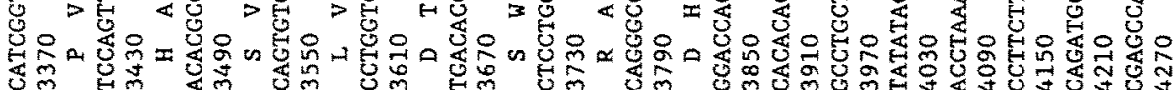

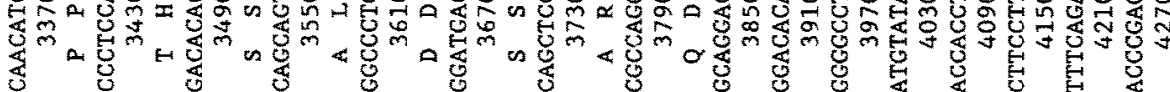

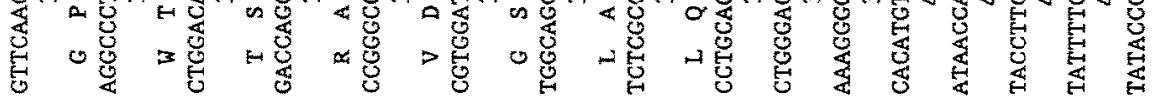

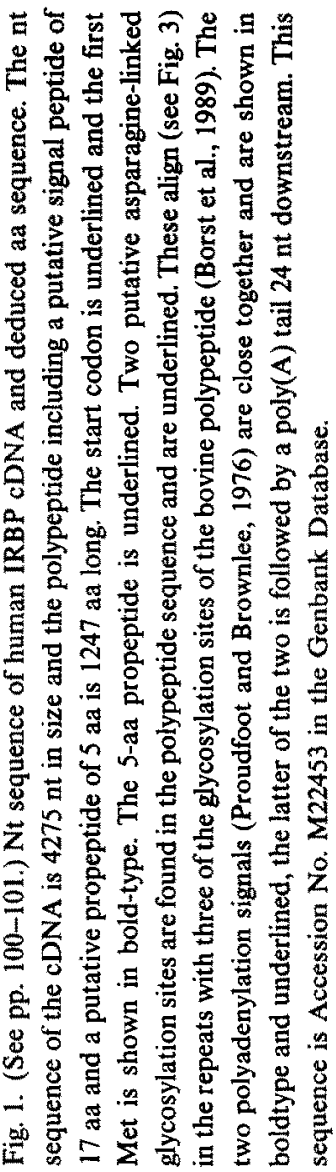

익

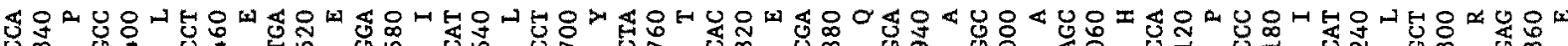
骑

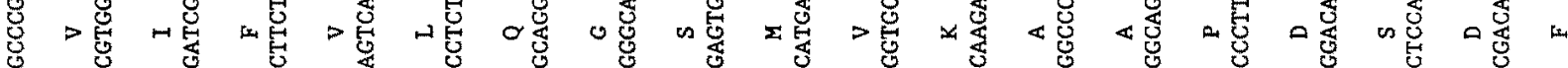

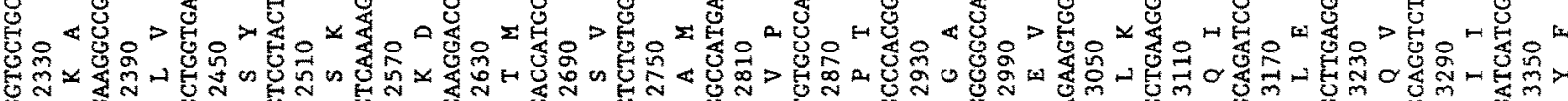

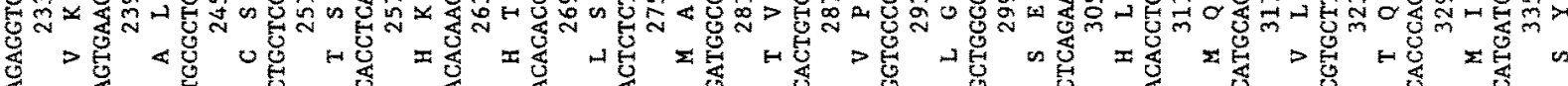

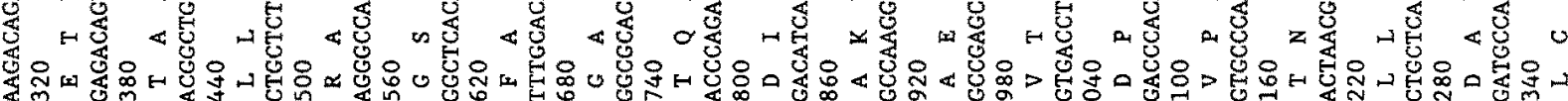

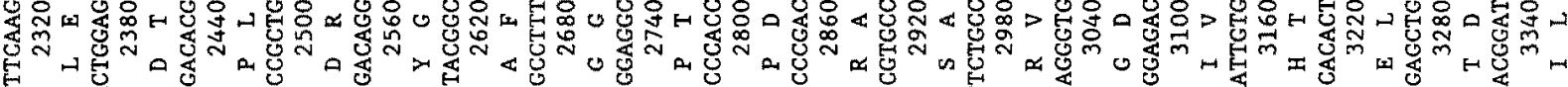
点 兽역

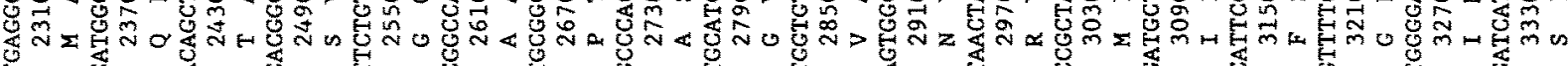

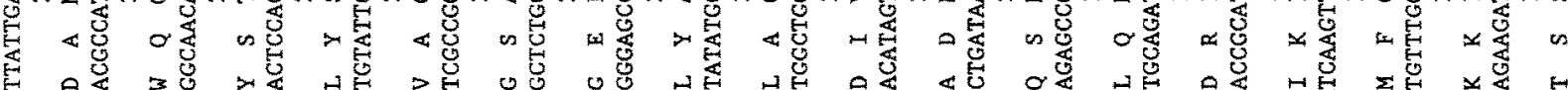

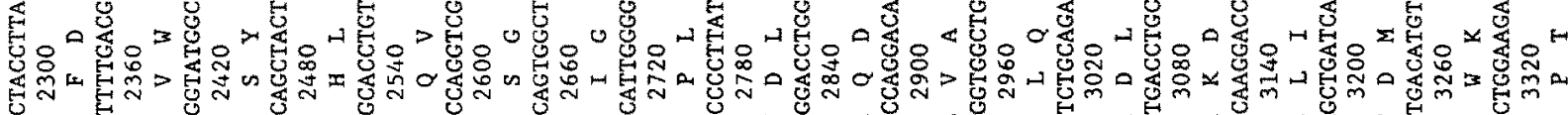

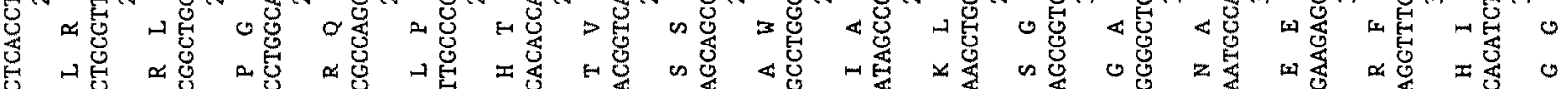

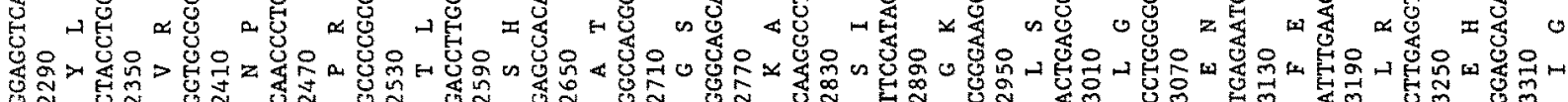

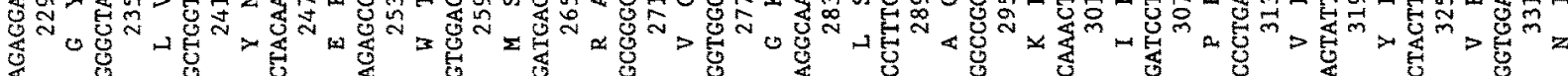

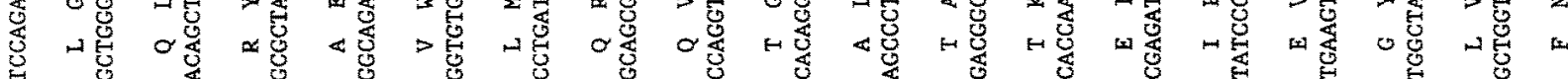


photoreceptor cells and pinealocytes (Van Veen et al., 1986) as indicated by the accumulation of mRNA for IRBP in these cells. IRBP binds retinoids (Wiggert et al., 1977) and fatty acids (Bazan et al., 1985) and its physiological role is thought to involve mediating or facilitating the transport of these ligands across the IPM (Chader et al., 1983). IRBP is a single large polypeptide of about $140 \mathrm{kDa}$ (Bridges et al,, 1986; 1987; Wiggert et al., 1986) and is the principal soluble protein of the IPM (Pfeffer et al., 1983). The gene (Borst and Nickerson, 1988) and cDNA (Barrett et al., 1985; Liou et al., 1986; Redmond et al., 1989) for bovine IRBP have been cloned and the sequences of these clones have been determined. The deduced polypeptide sequence of bovine IRBP contains 1264 aa and five putative glycosylation sites, totaling about $147 \mathrm{kDa}$. The bovine amino acid sequence consists of four repeats of about 300 aa and a 55-aa C-terminal extension. The repeats are $30-40 \%$ identical to each other. The bovine gene structure implies a mechanism by which the ancestral gene underwent quadruplication (Borst et al., 1989).

To study those parts of the IRBP molecule that are conserved and that may reflect structurally or functionally important sequences, it is necessary to determine the sequences of IRBP from several species. Here we report the isolation of several human cDNA clones and determination of the human IRBP cDNA sequence. Moreover, we compare the bovine and human CDNA and protein sequences in depth.

\section{MATERIALS AND METHODS}

J. Nathans kindly supplied the human retina cDNA library (Nathans et al., 1986) that we screened. A 900-bp Sall fragment from the coding portion of the bovine cDNA clonc pIRBP10-1800 (Redmond et al., 1989) served as the probe. It was labeled to about $5 \times 10^{8} \mathrm{cpm} / \mu \mathrm{g}$ by random priming (Feinberg and Vogelstein, 1983; 1984). The library was screened by minor modification of the method of Fritsch (Maniatis et al., 1982). The clones were plaque-purified by four serial rounds of screening. Three overlapping nonidentical cDNA clones were subcloned in both orientations into the Eco RI site of $\mathrm{pVZ1}$ [a vector similar to the pBluescript $\mathrm{KS}(+)$ vector (Stratagene), and kindly provided by $S$. Henikoff]. Single-stranded DNA was produced in $E$. coli strain BSJ72 (S. Henikoff) using the helper phage M13K07. Nucleotide sequences were obtained using the chain-terminator method (Sanger et al., 1977), [ ${ }^{35}$ S]dATP, and buffer-gradient gels (Biggin et al., 1983). Oligo primers were synthesized based on prior sequencing runs and a $2.2-\mathrm{kb}$ sequence of a human cDNA (Liou et al., 1987). The sequences were assembled and analyzed using GELIN, DBAUTO, DBUTIL, ANALYSEQ, and DIAGON (Staden, 1984a-e; Staden and McLachlan, 1982) and the IDEAS program package (Kanehisa, 1986).

\section{RESULTS AND DISCUSSION}

\section{(a) cDNA clones and sequence determination}

Roughly one clone in 800 in the human retina cDNA library containcd sequences hybridizing specifically with the bovine IRBP cDNA probe, a 900-bp fragment from pIRBP10-1800 (Redmond et al., 1989). This suggests that the IRBP mRNA has an abundance of roughly $0.1 \%$ in the retina, assuming that the production and amplification of the library has not distorted its proportion. After plaque purification and subcloning of $E c o$ RI fragments into the phagemid vector $p V Z 1$, we determined the nucleotide sequences of three clones (pIRBP18-3500, pIRBP19-1000, and pIRBP20-700). The three cDNAs are 3500,1000 , and $700 \mathrm{bp}$ long, respectively. The first clone is located centrally beginning about $577 \mathrm{nt}$ from the $5^{\prime}$ end, the second clone begins at the $5^{\prime}$ end, and the third clone makes up the last $700 \mathrm{nt}$ of the mRNA including some of the poly(A) tail. The sequences represent an accumulation of about $15500 \mathrm{nt}$ from 62 gel readings. The sequences are continuous on each strand of each of the three clones. There is more than a 3.5 -fold redundancy on average at each position of the sequence.

\section{(b) Nucleotide and amino acid sequences: start codons and signal peptides}

The nucleotide sequence and the deduced amino acid sequence are shown in Fig. 1. The nucleotide 
sequence is 4275 bp long, and includes 23 bp that were inverted in the cDNA clone pIRBP 19-1000 at the $5^{\prime}$ end, where such inversions commonly occur. This inversion was corrected by comparison with the bovine gene sequence and the corrected sequence is shown in Fig. 1. The protein is 1247 aa long and includes a putative signal peptide of 17 aa and a putative propeptide of 5 aa. The sequence begins with two successive Met codons. These are the first Met codons encountered in the nucleotide sequence. In accordance with Kozak's rules, the first Met codon bears resemblance to the consensus sequence found just upstream and downstream from the start codon (Kozak, 1984; 1986; 1987a,b). The optimal consensus sequence is CCACCATGG, while the first Met codon sequence is TCCCCATGA. The human sequence is very similar to the bovine sequence of TCCCCATGG. If the second Met were used, it would have an $A$ in the critical -3 position, closer to the optimal consensus, but this violates the notion that the first encountered Met codon is the start codon. The single bovine start codon aligns with the first of the two human Met codons, also suggesting that this first Met codon is the start codon in the human sequence. Comparing the amino acid sequences of the bovine and human signal and propeptides, 14 out of 22 aa are identical. Of the remaining differing residues, several appear to be conservative changes. As in the bovine signal sequence, there are charged residues near the beginning of the human sequence followed by hydrophobic residues in the middle. The human sequence contains a putative propeptide (GPTHL) similar but not identical to the bovine sequence (GPAHL). The differences in the residues of the propeptide may account for the observed heterogeneity at the $\mathbf{N}$ terminus seen among different species (Redmond et al., 1986; Fong et al., 1986). It may affect the proportion of shorter and longer forms of human IRBP found in the IPM (Borst and Nickerson, 1988).

\section{(c) Comparisons of the cDNA sequence}

An almost complete cDNA sequence recently reported (Fong and Bridges, 1988) and a previously reported sequence (Liou et al., 1987) corresponding to about one-half of the human mRNA differ in several important aspects from the one reported here. The differences between our sequence and the longer (Fong and Bridges, 1988) of these sequences are tabulated in Table I. These differences include several base substitutions and two significant reading-frame changes. One of these changes is at the C-terminal end of the protein and results in a tail that is 31 aa longer than in our sequence. This tail is not similar to the bovine polypeptide tail (Borst et al., 1989). This was determined by use of the SEQDP program in the IDEAS package (Kanehisa, 1986). This program assigned a score of -20 to the best match of the two tails. The average distance (score) of 20 shuffled sequences was $-23 \pm 6.2$ (standard deviation). In this program, lower scores indicate better matches. The other reading frame change in the Fong and Bridges (1988) sequence results in 24 aa in the fourth repeat (in our sequence aa residues 978-1001) that are not similar either to the corresponding bovine fourth repeat sequence or to repeat 1,2 , or 3 of the human sequence. In the shorter sequence (Liou et al., 1987), there is apparently an inversion of about $325 \mathrm{bp}$ at the $5^{\prime}$ end of their clone. There is no open reading frame in this orientation, but thcre is almost complete sequence identity when inverted and compared to our sequence and also substantial homology when compared to the bovine gene sequence (Borst et al., 1989). Table I also lists several changes that may represent normal sequence variations, and not sequencing errors. These may serve as useful polymorphisms in linkage studies; some presently are being verified as restriction-fragment-length polymorphisms in our laboratory.

\section{(d) Sizes of cDNA and mRNA}

Besides these sequence differences, our cDNA clones extend farther than the Fong and Bridges (1988) sequence at both the $5^{\prime}$ and $3^{\prime}$ ends. Our sequence extends $25 \mathrm{nt}$ beyond their sequence at the $5^{\prime}$ end. At the $3^{\prime}$ end, the Fong and Bridges (1988) sequence is missing $33 \mathrm{nt}$ which in our sequence contain the poly(A) signals at nt positions 4241 and 4255. A sequence of at least $40 \mathrm{~A}$ residues begins 24 nt downstream from the latter. This indicates that this clone (pIRBP20-700) was primed in its poly $(A)$ tail. The molecular size of the human IRBP mRNA determined by Northern blotting has been reported to be $5.2 \mathrm{~kb}$ in human retinas (Liou et al., 1987). In our laboratory, we have obtained values of $4.6 \mathrm{~kb}$ in 
TABLE I

Differences between two human IRBP cDNA sequences ${ }^{a}$

\begin{tabular}{|c|c|c|c|}
\hline \multicolumn{2}{|c|}{ Present work $^{b}$} & \multicolumn{2}{|c|}{ Fong and Bridges (1988) } \\
\hline nt position ${ }^{\mathrm{c}}$ & nt & $\begin{array}{l}\text { Corresponding } \\
\text { nt position }{ }^{\text {d }}\end{array}$ & $\mathrm{nt}$ \\
\hline \multicolumn{4}{|l|}{$5^{\prime}$-UTRR } \\
\hline 60 & $\mathrm{CT}$ & 35 & $\mathrm{~T}$ \\
\hline 110 & GT & 84 & $\mathbf{T}$ \\
\hline \multicolumn{4}{|c|}{ Coding region } \\
\hline 749 & $\mathrm{ACC}$ & 722 & CAA \\
\hline 1508 & $\mathbf{T}$ & 1481 & $\mathrm{C}$ \\
\hline 2769 & GC & 2742 & $\mathrm{CA}$ \\
\hline 3082 & $\mathrm{GC}$ & 3055 & $\mathrm{CG}$ \\
\hline 3113 & $\mathrm{G}$ & 3086 & GG \\
\hline 3123 & $\mathbf{T}$ & 3097 & $\mathrm{TG}$ \\
\hline 3134 & G & 3109 & $\mathrm{AGC}$ \\
\hline 3141 & A & 3118 & AGGAG \\
\hline 3185 & $\mathrm{G}$ & 3166 & GA \\
\hline 3549 & G & 3531 & $\mathrm{C}$ \\
\hline 3837 & $\mathrm{C}$ & 3819 & $\mathrm{CC}$ \\
\hline 3854 & $\mathrm{C}$ & 3837 & $\mathrm{CG}$ \\
\hline \multicolumn{4}{|l|}{ 3'-UTR } \\
\hline 4078 & $\mathrm{~T}$ & 4062 & $\mathrm{C}$ \\
\hline 4129 & GGGT GGTATTTTT & 4113 & TGCACCCC \\
\hline 4167 & T T T TC & 4146 & CTTTC \\
\hline 4242 & A & 4222 & $\mathrm{C}$ \\
\hline
\end{tabular}

a This table shows the differences between the two existing human IRBP cDNA sequences.

b The nt positions and nt listed above are taken from the sequence given in Fig. 1.

c The numbers in this column correspond to the first $\mathrm{nt}$ shown in the immediately adjacent column.

d The numbers in this column are for the first nt in the column on the right and the numbering is from Fong and Bridges (1988). These columns show the differences in $\mathrm{nt}$ at the corresponding positions in the sequence shown in Fig. 1.

normal human retinas and $4.4 \mathrm{~kb}$ in cultured human retinoblastoma (Y-79) cells (Inouye et al., 1989). From our cDNA sequence, we predict that the mRNA size should be $4.3 \mathrm{~kb}$ excluding the poly(A) tail. Also, Liou et al. (1989) report a value of the molecular size of the mRNA of at least $4285 \mathrm{nt}$, excluding the poly(A) tail, based on nucleotide sequence analysis. They did not report a cDNA and, thus, could not state definitively that the poly(A) signal they encountered is functional. The first encountered poly(A) signal in their sequence is the same as the latter we report here. Our work shows that this signal is functional. Thus, it seems likely that the size of the principal species of human IRBP mRNA is $4.3 \mathrm{~kb}$ excluding the poly(A) tail.

\section{(e) Comparison of bovine and human $3^{\prime}$-untranslated regions}

The $3^{\prime}$-UTR of the human IRBP mRNA is much shorter than the corresponding sequence from bovine mRNA. Borst et al. (1989) and Redmond et al. (1989) report the sequences of the bovine gene and cDNAs, respectively. In the cow, the $3^{\prime}$-UTR is $1988 \mathrm{nt}$ long. In contrast, the human $3^{\prime}$-UTR is only $416 \mathrm{nt}$ in size. Homology is still evident in the UTRs and is shown in Fig. 2 by dot matrix analysis of the two cDNAs. The pattern in the homology suggests that either there was a large insertion into the ancestor to the bovine sequence or a large deletion from the ancestor to the human sequence. There is 


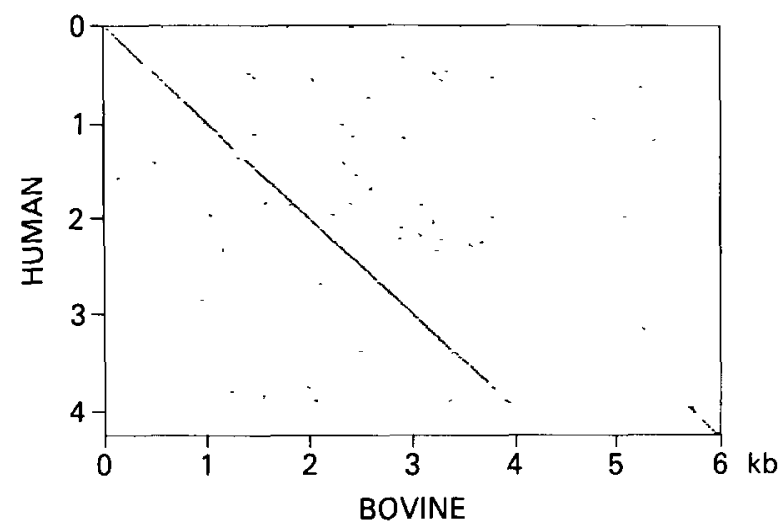

Fig. 2. Dot matrix comparison (Maizel and Lenk, 1981) of the human and bovine cDNA sequences of IRBP. The bovine sequence is on the abscissa and the human sequence on the ordinate. The DIAGON program (Staden, 1984d) was used with a SPAN of 13 and a score of 11 using the identity algorithm. The analysis shows a major insertion into the bovine sequence or a major deletion in the human sequence in the $3^{\prime}$-UTRs. The diagonal line in the lower right corner of the matrix indicates that the two cDNAs retain sequence similarity with each other in the last $270 \mathrm{nt}$ of their cDNAs. Weak and badly broken lines of homology parallel to major diagonal can be detected by tilting the figure and looking along the major axis. These weak lines indicate the repeat structure which is much more obvious at the protein level.

sequence similarity in the $3^{\prime}$ portions of the two cDNA sequences; in the final $266 \mathrm{nt}$ there is $75 \%$ identity. Because of the highly variable size of the IRBP mRNAs among different mammalian species (Inouye et al., 1989), it will be interesting to discriminate between these two possibilities (insertion vs. deletion) in the evolutionary history of the bovine and human IRBP genes.

\section{(f) Quadruplication within the protein}

As is the case with bovine protein, human IRBP contains a fourfold repeat structure. Each repeat is about 300 aa long. This suggests that the ancestral gene encoded a polypeptide of approx. 300 aa that underwent a quadruplication. Each human repeat is about $30-40 \%$ identical with the other repeats (Table II). The evenness in sequence similarity among the four repeats suggests that they began to diverge from each other at about the same time. This suggests that the evolutionary quadruplication may have occurred within a short period of time, perhaps near the time of radiation of the vertebrates. It is
TABLE II

Similarities among the four repeats of human IRBP

\begin{tabular}{lllll}
\hline & 1 & 2 & 3 & \multicolumn{2}{c}{4} \\
\hline & & & \multicolumn{2}{c}{ Homology score ${ }^{\mathrm{a}}$} \\
2 & - & -420 & -503 & -541 \\
3 & $31.9 \%$ & - & -477 & -469 \\
4 & $34.0 \%$ & $36.5 \%$ & - & -622 \\
& $35.8 \%$ & $34.5 \%$ & $37.0 \%$ & - \\
\hline
\end{tabular}

a The homology score is based on the empirical weight matrix (Dayhoff et al., 1979), which is based on substitutions observed among members within a protein family. The score was calculated using the SEQHP program in the IDEAS program package developed by Kanehisa (1986). The lower the score, the greater the similarity of the two sequences.

b The \% identity is the percentage of identical aa between the pair of repeats aligned by the SEQHP program.

interesting, however, that repeats 3 and 4 are the most similar (Table II) among the four human repeats, and 3 and 4 are also the most tightly conserved between the bovine and human species (Table III). The closer conservation of these two repeats, both intraspecies and interspecies, suggests common evolutionary pressures, and may suggest common functions of the two repeats somewhat different from the functions of repeats 1 and 2 . This may be important in the determination of the struc-

\section{TABLE III}

Similarities between homologous repeats of bovine and human IRBPs

\begin{tabular}{lll}
\hline $\begin{array}{l}\text { Number of bovine vs. } \\
\text { human repeats }^{\mathrm{a}}\end{array}$ & $\begin{array}{l}\text { Identity }^{\mathrm{b}} \\
(\%)\end{array}$ & $\begin{array}{l}\text { Homology } \\
\text { score }^{\mathrm{c}}\end{array}$ \\
\hline 1 vs. 1 & 82.0 & -1237 \\
2 vs. 2 & 80.1 & -1246 \\
3 vs. 3 & 90.8 & -1332 \\
4 vs. 4 & 86.2 & -1312 \\
\hline
\end{tabular}

a Repeats 1 through 4 of human IRBP are aa residues $1-300$, $301-612,613-912$, and 913-1212, respectively. In bovine, repeats 1 through 4 are aa residues $1-301,302-609,610-910$, and 911-1209, respectively.

b The identity is the \% of identical residues found using the alignments obtained from the SEQHP program of Kanehisa (1986).

c The homology score is from the SEQHP program of Kanehisa (1986); the lower scores reflect closer sequence similarity. 


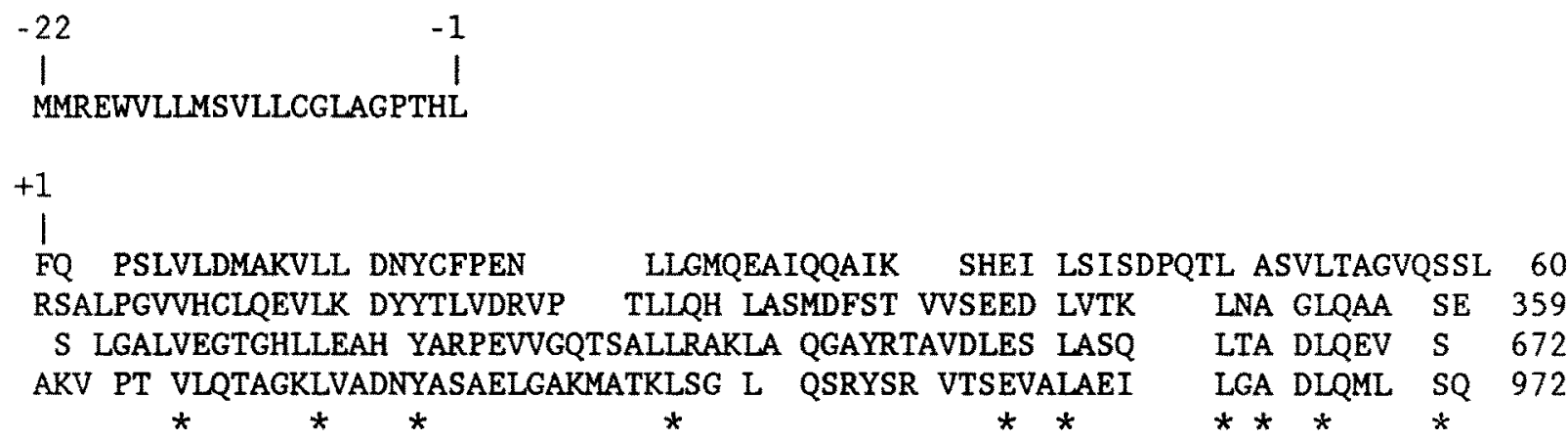

NDPRL VISYEPSTPE PPPQVPALTSLSEE ELIAWLQRGLRH E $\quad$ VLEGNVGYLRVDSVPGQE 120 DPRLLVRAIGPTETPSWPAPDAAAED SPGVAPELPEDEAIRQALVDSVFQVSVLPGNVGYLRFD 4423 GDHRLLVFHS PGELVVEEAPPPPPAV PSPE ELTY LIEALFKTE $\quad$ VLPGQLGYLRFDAMA EL 732 DPHLKAAHI P ENAKDRIPGIVPMQIPSPEVFEELIKFSFHTN $\quad$ VLEDNIGYLRFDMFGDGE 1032 * * * * * * * * * * * *****

VLSMMGEF L VAH VWGNLMGTSALVLDLRHCTGGQVS GIPYIISYLH PGNTI LHVDTIYN 179 SFADASVLGVLAPYVLRQVWEPLQDTEHLIMDLRMNPGGPSS AVPLLLSYFQG PEAGPVHLF TTYDR 490 ETVKA VGPQL VRL VWQQLVDTAALVIDLRYNPGSY STAIPLLCSYFFEAEPRQH L $\quad$ YSVFD 792 LLTQ VSRLL VEHI WKKIMHTDAMIIDMRFNIGGPTS SIPILCSYFFDEGPPVL LDKI YS 1091

RPSNTTT EIWTLPQVLGERY GADKDVVVLTSSQTRGVAEDTAHILKQMR RAIVV GERTGGG 240 R TNITQ EMFSHMELPGPRYSTQRGV YLLTSHRTATAAEEFAFL MQSLGWATLV GEITAG 549 RA TSKVTEVWTLPQVAGQRY GSHKDLYILMSHTSGSAAEAFAHT MQDLQRAT VIGEPTAGG 853 RP DDSVSELWTHAQVVGERY GSKKSMVILTSSVTAGTAEEFTYI MKRLGRAL VIGEVTSGG 1153 * $* * * * * * * * * * * * * *$

ALDLRK LRIGESDFFFTVPVSRSLGPLGGGSQTWEGSGVLPC VGTPAEQALEKALAILTL 300 NLLHTRT VPL LDTPEGSLALTVPVL TFIDNHG EAWLGGGVVPDAIVLA EEALDKAQEVLEFHQ 612 ALSVGIYQVGSSPLYASMP TOMAMSATT G KAWDIAGVEPDITVPMS E ALSIAODIVALR 912 CQPPQTYHVDDTNLYLTIP TARSVGASD GS SWEGVGVTPHVVVPAE E ALARAKEMLQHNQ 1212 * $* * * * * * * * *$

LRVKRSPGLQDHL

I

$+1225$

Fig. 3. Alignment of the four repeats in the human IRBP sequence. Asterisks indicate that the residues are identical in all four repeats. The putative carbohydrate sites are underlined. The numbering of the amino acid sequence is the same as in Fig. 1 . The numbers on the right side correspond to the rightmost aa on any line.

ture and location of the ligand-binding sites in several repeats. The repeat structure of the human sequences is shown in Fig. 3. There are several residues that are common among the four human repeats as indicated in the figure. We presume that these residues are important for either the function of IRBP or for the maintenance of the protein structure, although some of these residues are among those that are abundant in proteins in general. Other analyses of the human polypeptide sequence such as secondary structure and hydrophobicity have been performed (not shown). These analyses in general show similar values among corresponding parts of the four repeats as in the bovine sequence (Borst et al., 1989).

\section{(g) Conservation of glycosylation sites}

IRBP is known to be glycosylated. The bovine IRBP sequence has five putative sites for Asn-linked glycosylation at least three of which are glycosylated 
(Borst et al., 1989). Previously, we have shown that at least one of the bovine carbohydrate sites has been lost from the human sequences (Nickerson et al., 1988), based on the nucleotide sequence of a human genomic clone for IRBP. Here we show that the human sequence contains only two of the putative glycosylation sites on Asn-183 and Asn-493 in the first and second protein repeats. Both are in positions homologous to the bovine glycosylation sites. The two glycosylation sites are in identical positions in the human repeats (Fig. 3). They also align in identical positions with three bovine carbohydrate sites in repeats 1, 2, and 4 (Borst et al., 1989).

\section{(h) Conclusions}

We have cloned and sequenced cDNA clones corresponding to the human IRBP mRNA. These sequences clearly establish the size of the IRBP mRNA as $4.3 \mathrm{~kb}$ excluding the poly(A) tail. The major evolutionary difference between the bovine and human IRBP mRNAs is a $1.58 \mathrm{~kb}$ insertion/ deletion in the $3^{\prime}$-UTR. As in the bovine case, the human gene appears to have undergone a quadruplication of the ancestral gene. Both in human and bovine, repeats 3 and 4 are the most similar, implying that their functions may be the most related. In addition to providing sequence information for evolutionary comparisons, these clones will help to define possible polymorphisms. Also, these clones will be useful in expression systems for the production of human IRBP protein or fragments necessary to study its biochemical properties (e.g., retinoid binding). Moreover, these clones will be critical in determining potential epitopes in human IRBP that might be involved in experimental autoimmune uveitis (Gery et al., 1986).

\section{REFERENCES}

Barrett, D.J., Redmond, T.M., Wiggert, B., Oprian, D.D., Chader, G.J. and Nickerson, J.M.: cDNA clones encoding bovine interphotoreceptor retinoid binding protein. Biochem. Biophys. Res. Commun. 131 (1985) 1086-1093.

Bazan, N.G., Reddy, T.S., Redmond, T.M., Wiggert, B. and Chader, G.J.: Endogenous fatty acids are covalently and noncovalently bound to interphotoreceptor retinoid-binding protein in the monkey retina. J. Biol. Chem. 260 (1985) $13677-13680$.
Biggin, M.D., Gibson, T.J. and Hong, G.F.: Buffer gradient gels and ${ }^{35} \mathrm{~S}$ label as an aid to rapid DNA sequence determination. Proc. Natl. Acad. Sci. USA 80 (1983) 3963 3965.

Borst, D.E. and Nickerson, J.M.: The isolation of a gene encoding interphotoreceptor retinoid-binding protein. Exp. Eye Res. 47 (1988) 825-838.

Borst, D.E., Redmond, T.M., Elser, J.E., Gonda, M.A., Wiggert, B., Chader, G.J. and Nickerson, J.M.: Interphotoreceptor retinoid-binding protein: gene characterization, protein repeat structure, and its evolution. J. Biol. Chem. 264 (1989) 1115-1123.

Bridges, C.D., Liou, G.I., Alvarez, R.A., Landers, R.A., Landry Jr., A.M. and Fong, S.L.: Distribution of interstitial retinolbinding protein (IRBP) in the vertebrates. J. Exp. Zool. 239 (1986) 335-346.

Bridges, C.D., Foster, R.G., Landers, R.A. and Fong, S.L.: Interstitial retinol-binding protein and cellular retinal-binding protein in the mammalian pineal. Vision Res. 27 (1987) 2049-2060.

Bunt-Milam, A.H. and Saari, J.C.: Immunocytochemical localization of two retinoid-binding proteins in vertebrate retina. J. Cell Biol. 97 (1983) 703-712.

Chader, G.J., Wiggert, B., Lai, Y.-L. and Fletcher, R.: Interphotoreceptor retinoid-binding protein: a possible role in retinoid transport to the retina. Prog. Ret. Res. 2 (1983) 163-189.

Dayhoff, M.O., Schwartz, R.M. and Orcutt, B.C.: A model of evolutionary change in proteins. In Dayhoff, M.O. (Ed.), Atlas of Protein Sequence and Structure. National Biomedical Research Foundation, Silver Spring, MD, 1979, pp. 345-352.

Feinberg, A.P. and Vogelstein, B.: A technique for radiolabelling DNA restriction endonuclease fragments to high specific activity. Anal. Biochem. 132 (1983) 6-13.

Feinberg, A.P. and Vogelstein, B.: A technique for radiolabelling DNA restriction endonuclease fragments for high specific activity. Addendum. Anal. Biochem. 137 (1984) 266-267.

Fong, S.-L. and Bridges, C.D.B.: Internal quadruplication in the structure of human interstitial retinol-binding protein deduced from its cloned cDNA. J. Biol. Chem. 263 (1988) $15330-15334$.

Fong, S.-L., Cook, R.G., Alvarez, R.A., Liou, G.I., Landers, R.A., and Bridges, C.D.B.: N-terminal sequence homologies in interstitial retinol-binding proteins from 10 vertebrate species. FEBS Lett. 205 (1986) 309-312.

Gery, I., Wiggert, B., Redmond, T.M., Kuwabara, T., Crawford, M.A., Vistica, B.P. and Chader, G.J.: Uveoretinitis and pinealitis induced by immunization with interphotoreceptor retinoid-binding protein. Invest. Ophthalmol. Vis. Sci. 27 (1986) 1296-300.

Inouye, L.N., Albini, A., Chader, G.J., Redmond, T.M. and Nickerson, J.M.: mRNA for interphotoreceptor retinoidbinding protein (IRBP): distribution, and size diversity in vertebrate species. Exp. Eye Res. (1989) in press.

Kanehisa, M.: IDEAS: Integrated Database and Extended Analysis System for Nucleic Acids and Proteins. User Manual. NCI Frederick Cancer Research Facility, Frederick, MD, 1986. 
Kozak, M.: Compilation and analysis of sequences upstream from the translational start site in eukaryotic mRNAs. Nucleic Acids Res. 12 (1984) 857-872.

Kozak, M.: Point mutations define a sequence flanking the AUG initiator codon that modulates translation by eukaryotic ribosomes. Cell 44 (1986) 283-292.

Kozak, M.: At least six nucleotides preceding the AUG initiator codon enhance translation in mammalian cells. J. Mol. Biol. 196 (1987a) 947-950.

Kozak, M.: An analysis of 5'-noncoding sequences from 699 vertebrate messenger. Nucleic Acids Res. 15 (1987b) $8125-8148$.

Liou, G.I., Fong, S.L., Beattre, W.G., Cook, R.G., Leone, J., Landers, R.A., Alvarez, R.A., Wang, C. and Bridges, C.D.B.: Bovine interstitial retinol-binding protein (IRBP) - isolation and sequence analysis of CDNA clones, characterization and in vitro translation of mRNA. Vision Res. 26 (1986) 1645-1653.

Liou, G.I., Fong, S.L., Gosden, J., Van Tuinen, P., Ledbetter, D.H., Christie, S., Rout, D. and Bhattacharya, S.: Human interstitial retinol-binding protein (IRBP): cloning, partial sequence, and chromosomal localization. Somat. Cell. Mol. Genet. 13 (1987) 315-323.

Liou, G.I., Ma, D.-P., Yang, Y.-W., Li, G., Chui, Z. and Baehr, W.: Human interstitial retinoid-binding protein: gene structure and primary sequence. J. Biol. Chem. (1989) (in press).

Maizel Jr., J.V. and Lenk, R.P.: Enhanced graphic matrix analysis of nucleic acid and protein sequences. Proc. Natl. Acad. Sci. USA 78 (1981) 7665-7669.

Maniatis, T., Fritsch, E.F. and Sambrook, J.: Molecular Cloning. A Laboratory Manual. Cold Spring Harbor Laboratory, Cold Spring Harbor, NY, 1982, pp. 322-323.

Nathans, J., Thomas, D. and Hogness, D.S.: Molecular genetics of human color vision: the genes encoding blue, green, and red pigments. Science 232 (1986) 193-202.

Nickerson, J.M., Borst, D.E., Redmond, T.M., Hershfield, B., Si, J.-S., Albini, A., Inouye, I., Toffenetti, J. and Chader, G.: Molecular genetics of interphotoreceptor retinoid-binding protein. In Piatigorsky, J, Shinohara, T. and Zelenka, P.S. (Eds.), Molecular Biology of the Eye: Genes, Vision, and Ocular Diseases. Liss, New York, 1988, pp. 93-105.

Pfeffer, B., Wiggert, B., Lee, L., Zonnenberg, B., Newsome, D. and Chader, G.: The presence of a soluble interphotoreceptor retinol-binding protein (IRBP) in the retinal interphotoreceptor space. J. Cell. Physiol. 117 (1983) 333-341.

Proudfoot, N.J. and Brownlee, G.G.: 3' non-coding region sequences in eukaryotic messenger RNA. Nature 263 (1976) 211-214.
Redmond, T.M., Wiggert, B., Robey, F.A. and Chader, G.J.: Interspecies conservation of structure of interphotoreceptor retinoid-binding protein. Similarities and differences as adjudged by peptide mapping and $\mathrm{N}$-terminal sequencing. Biochem. J. 240 (1986) 19-26; Erratum 242 (1987) 935.

Redmond, T.M., Si, J.-S., Barrett, D.J., Borst, D.E., Rainier, S., Kotake, S., Gery, I. and Nickerson, J.M.: Expression of an immunopathogenic fusion protein derived from a bovine interphotoreceptor retinoid-binding cDNA clone. Gene 80 (1989) 109-118.

Rodrigues, M.M., Hackett, J., Gaskıns, R., Wiggert, B., Lee, L., Redmond, M. and Chader, G.J.: Interphotoreceptor retinoidbinding protein in retinal rod cells and pineal gland. Invest. Ophthalmol. Vis. Sci. 27 (1986) 844-50.

Sanger, F., Nicklen, S. and Coulson, A.R.: DNA sequencing with chain-terminating inhibitors. Proc. Natl. Acad. Sci. USA 74 (1977) 5463-5467.

Staden, R.: Computer methods to aid the determination and analysis of DNA sequences. Biochem. Soc. Trans. 12 (1984a) 1005-1008

Staden, R.: A computer program to enter DNA gel reading data into a computer. Nucleic Acids Res. 12 (1984b) 499-503.

Staden, R.: Computer methods to locate signals in nucleic acid sequences. Nucleic Acids Res. 12 (1984c) 505-519.

Staden, R.: Graphic methods to determine the function of nucleic acid sequences. Nucleic Acids Res. 12 (1984d) 521-538.

Staden, $\mathbf{R}$ : Measurements of the effects that coding for a protein has on a DNA sequence and their use for finding genes. Nucleic Acids Res. 12 (1984e) 551-567.

Staden, R. and McLachlan, A.D.: Codon preference and its use in identifying protein coding regions of long DNA sequences. Nucleic Acids Res. 10 (1982) 141-156.

Van Veen, T., Katial, A., Shinohara, T., Barrett, D.J., Wiggert, B., Chader, G.J. and Nickerson, J.M.: Retinal photoreceptor neurons and pinealocytes accumulate mRNA for interphotoreceptor retinoid-binding protein (IRBP). FEBS Lett. 208 (1986) 133-137.

Wiggert, B., Bergsma, D.R., Lewis, M. and Chader, G.J.: Vitamin A receptors: retinol binding in neural retina and pigment epithelium. J. Neurochem, 29 (1977) 947-954.

Wiggert, B., Derr, J.E., Fitzpatrick, $M$. and Chader, G.J.: Vitamı $A$ receptors of the retina: differential binding in light and dark. Biochim. Biophys. Acta 582 (1979) 115-121.

Wiggert, B., Lee, L., Rodrigues, M., Hess, H., Redmond, T.M. and Chader, G.J.: Immunochemical distribution of interphotoreceptor retinoid-binding protein in selected species. Invest. Ophthalmol. Vis. Sci. 27 (1986) 1041-1049. 